\title{
Relationship Among Obesity Awareness, Emotional Eating, and Obesity in Middle School Children
}

\author{
(1) Gülçin Özalp Gerçeker, (1) Murat Bektaş \\ Dokuz Eylül University Faculty of Nursing, Department of Pediatric Nursing, İzmir, Turkey
}

\begin{abstract}
Aim: This study was carried out as a cross-sectional study to evaluate the relationships between obesity awareness, emotional eating, and obesity in middle school children.

Materials and Methods: The sample of the study comprised a total of 421 children who were 10-14 years of age and attended the fifth, sixth, seventh, or eighth grades. The data were collected using a socio-demographic data collection form, the Obesity Awareness scale, and the Emotional Eating scale. The heights and weights of the children were measured by the researchers and their body mass index (BMI) percentiles were calculated. The data were analyzed using Pearson's correlation analyses.

Results: Of the children, $14.7 \%$ were obese, and $13.8 \%$ were overweight according to the BMI percentile. There was no relationship between obesity, obesity awareness, and emotional eating ( $p>0.05)$.

Conclusion: The study found that emotional eating and obesity awareness did not affect middle school children's obesity.

Keywords: Children, middle-school, obesity, awareness, emotional eating
\end{abstract}

\section{Introduction}

Eating is a biological and behavioral process that begins in the first year of life and serves as a foundation for growth and development (1). The eating behavior that emerges as a response to an emotional state is referred to as emotional eating. This eating behavior is not based on the feeling of hunger and may lead to obesity $(2,3)$.

The ratio of childhood obesity has doubled in the last 30 years (4). The ratio of obese children and adolescents in the US was $16.9 \%$ (5). According to the investigation report on monitoring the growth of school children (6-10-year-old age group) project in Turkey by the General Directorate of Basic Health Services of the Turkish Ministry of Health (6) $8.5 \%$ of children were obese and the ratios of overweight children in cities and rural areas were $16.3 \%$ and $11.9 \%$, respectively. There is a global increase in the prevalence of obesity and being overweight in children and adolescents.

Researchers have the important task to investigate the causes of obesity such as sedentarism, emotional eating, parents, and children's awareness about obesity. Demir and Bektas (7) reported that eating behaviors and parental feeding styles affect the occurrence of obesity in childhood. Parents may influence their children's eating behaviors and result in high levels of disinhibited emotional eating in early adolescents (8). There are only a small number of studies that investigate the relationship between emotional eating and obesity in children $(9,10)$.

\section{Address for Correspondence}

Assoc. Prof. Cülçin Özalp Gerçeker, Dokuz Eylül University Faculty of Nursing, Department of Pediatric Nursing, İzmir, Turkey Phone: +90 2324126961 E-mail: gulcinozalp@gmail.com ORCID: orcid.org/0000-0002-2229-616X Received: 24.06.2019 Accepted: 12.02.2020

${ }^{\circ}$ Copyright 2021 by Ege University Faculty of Medicine, Department of Pediatrics and Ege Children's Foundation The Journal of Pediatric Research, published by Galenos Publishing House. 
Emotional eating in children can be associated with deficits in emotion regulation. It may therefore represent a risk factor for becoming overweight or obese children/ adolescents (11). In adults, emotional eating has been found to correlate positively with weight status (12). We think that emotional eating may be associated with obesity in children. Increased awareness about obesity among children will help to reduce the risk of obesity and also chronic diseases (13). Although the child is obese or overweight, the awareness of obesity may be low and the child may be obese or overweight due to emotional eating. With this study, this deficiency in the literature can be closed. Some instruments such as emotional eating or obesity awareness can evaluate the vulnerability and risk factors for early adolescents $(13,14)$. It can be a way to control obesity in children. This study aimed to determine the relationships between obesity awareness, emotional eating, and obesity in middle school children.

\section{Materials and Methods}

\section{Study Design and Participants}

This cross-sectional study evaluated the relationships between obesity awareness, emotional eating, and obesity in middle school children.

The population of the study was made up of 680 students who were 10-14 years of age and attending the fifth, sixth, seventh, or eighth grades of a middle school in Izmir affiliated with the Provincial Directorate for National Education, a metropolitan region located in the western part of Turkey. This school was selected as no studies about obesity had been conducted there previously and the majority of children were from middle-income families.

The criteria for inclusion in the sample group were: a) being a middle school student, b) being 10-14 years of age, c) voluntarily participating in the study with written consent forms from the participants and their parents, d) not having deceased parents and e) having access to the parents' height and weight data. It was aimed to reach the whole population $(n=680)$. No sample selection method was used, and 421 students who volunteered to participate in the study, met the inclusion criteria, and filled out the forms were included in the study sample. The participation rate was $61 \%$ in this study.

\section{Data Collection}

The data were collected by the researcher in a classroom environment during a visit to the school between February
2017 and June 2017. A socio-demographic data collection form, the Obesity Awareness scale (OAS), and the Emotional Eating scale (EES-C) were used for data collection. The researcher informed the children about the purpose of the study. Informed written consent from parents was received through the children. Verbal consent from the children was also received. The heights and weights of the children were measured by the researcher between 9:30-12:00 a.m. before the meal. All of the children were wearing clothes (only shirt and skirt/pants), the children's shoes were removed before the measurement. Bodyweight and height were measured by a digital weighing scale and a stadiometer and recorded on the demographic data collection form. The digital weighing scale was calibrated before the study. Body mass index (BMI) and BMI percentile were calculated for each child using the auxology program according to Turkish children's BMI references (15). In the auxology program, $\mathrm{BMI}$ and $\mathrm{BMI}$ percentile were calculated by entering the children's date of birth, weight, and height. Underweight is defined as $<5^{\text {th }}$ percentile, normal-weight is defined as $5^{\text {th }}$ to $<85^{\text {th }}$ percentile, overweight is defined as between the $85^{\text {th }}$ to $<95^{\text {th }}$ percentile, and obese is defined as $\geq 95^{\text {th }}$ percentile.

The data collection forms were handed to the children who were asked to disclose demographic data and answer the scale items. In addition to the written consent form, the parents were also asked to answer some questions about themselves on the data collection form. The BMls of the parents were calculated using the height and weight values they gave. The BMIs of the parents were categorized as follows; underweight is defined as $<18.5$, normal weight is defined as 18.5-24.9, overweight is defined as 25.0-29.9, and obese is defined as $>30.0$.

Socio-demographic Data Collection Form: This form includes questions for children about their grade, age, gender, time spent with computers, phones or television, frequency of having breakfast, frequency of eating junk food, frequency of eating fast food, and contentment with the appearance of their bodies. It also includes questions for their parents about their own heights and weights (8-10).

The Obesity Awareness Scale (OAS): This scale was developed by Allen (16). It has 23 items in 3 subdimensions that evaluate: a) obesity awareness ( 8 items) and knowledge about risk factors (such as whether childhood obesity is increasing in school, society, and country), b) nutrition ( 7 items), dietary habits of the individual and the effects of nutrients on health (such as whether overeating at each meal causes obesity) and c) physical 
activity ( 8 items), the effect of physical activity on health and weight (such as whether exercising for at least 60 minutes per day is necessary to be healthy). The scale is a four-point Likert scale from negative to positive. Its internal consistency coefficient was reported to be 0.80 . The validity and reliability study for the Turkish scale was performed by Kafkas and Özen (17), and its Cronbach's alpha value was good at 0.87. Confirmatory factor analysis showed that the scale had an appropriate structure and that the Turkish OAS is a valid and reliable measurement tool (17). The Cronbach's alpha value was 0.90 for this study. Scale permission was received from the authors via mail.

Emotional Eating Scale (EES-C): This scale evaluates the emotional eating status of children between 8-17 years old. The original adult-based scale was adapted by TanofskyKraff et al. (18) into a children's and adolescents' EES-C. The scale is composed of 25 items and three subdimensions concerning the reason for eating an excess amount of food; anxiety, anger, and frustration (EES-C-AAF), depressive symptoms (EES-C-DEP), and feeling unsettled (EES-C-UNS). The total variance of these three subdimensions was $67.2 \%$, factor loads were between 0.61-0.79 for EES-C-AAF; 0.570.84 for EES-C-DEP; and 0.52-0.72 for EES-C-UNS. The Cronbach's alpha values were $0.95,0.92$, and 0.83 for the three subdimensions, respectively. In this five-point Likert scale, the answers varied between 1 (I never want to eat) to 5 (I want to eat a lot). As scores on this scale increase, so does eating as a response to emotional states. This scale was translated into Spanish and found to be a valid and reliable scale for the Spanish population (14). The validity and reliability study for the Turkish population was performed by Bektas et al. (19), and the Cronbach's alpha values for this scale and its subdimensions were $0.90,0.86,0.76$, and 0.71 , respectively. The total correlation of the items ranged from 0.57 to 0.99 . The EES-C is a valid and reliable scale for determining the emotional eating of Turkish children and adolescents (19). The Cronbach's alpha value was 0.87 for this study. Scale permission was received from the authors via mail.

\section{Ethical Approval}

Before the research was conducted, permits were obtained from the owners of the scales used in the research via email. The written consent of Dokuz Eylül University Non-invasive Research Ethics Board was obtained in a decision numbered (3019-GOA, 2016/29-25). Permission was also obtained from the İzmir Provincial Directorate for National Education to conduct the study (12018877604.01.01.-E.13824002).

\section{Statistical Analysis}

The data were analyzed using SPSS (22.0) software. The compliance of the parameters to normal distribution was evaluated through the Shapiro-Wilk test. Percentages and means were used to evaluate the socio-demographic characteristics. Their BMI percentile was categorized. The characteristics of the children were analyzed using the $x^{2}$ test and t-test. One-Way ANOVA analysis was used to compare the students' emotional eating and obesity awareness scores according to BMI percentile. The relationships between the OAS, the EES-C, and their subdimensions and obesity (obese $\geq 95^{\text {th }}$ percentile or not) were analyzed using Pearson's correlation analysis. The threshold for statistical significance was $p<0.05$.

\section{Results}

\section{Children Characteristics}

The children's age and gender according to BMI percentile are given in Table I. Of the students, $14.7 \%$ were obese $(n=62), 13.8 \%$ were overweight $(n=58), 62 \%$ had a normal weight $(n=261)$, and $9.5 \%$ were underweight $(n=40)$. Of the students, $45.4 \%$ were females $(n=191)$. There was a statistical difference between gender and BMI percentile $(p<0.05)$. The students' mean age was $12.1 \pm 1.0$ years $[\operatorname{minimum}(\min )=10$, maximum $(\max )=14]$. Their

Table I. Children's age and gender according to body mass index percentile

\begin{tabular}{|c|c|c|c|c|c|}
\hline Socio-demographics & $\begin{array}{l}\text { Obese } \\
(n=62)\end{array}$ & $\begin{array}{l}\text { Overweight } \\
(n=58)\end{array}$ & $\begin{array}{l}\text { Normal weight } \\
(n=261)\end{array}$ & $\begin{array}{l}\text { Underweight } \\
(n=40)\end{array}$ & $\mathbf{p}$ \\
\hline Age (mean years \pm SD) & $12.0 \pm 1.2$ & $12.2 \pm 1.2$ & $12.1 \pm 1.0$ & $11.9 \pm 0.8$ & $0.506^{*}$ \\
\hline \multicolumn{6}{|l|}{ Gender } \\
\hline Girls (n, \%) & $10(5.2)$ & $28(14.7)$ & $128(67)$ & $25(13.1)$ & \multirow{2}{*}{$0.000^{* *}$} \\
\hline Boys ( $n, \%)$ & $52(22.6)$ & $30(13)$ & $133(57.8)$ & $15(6.5)$ & \\
\hline
\end{tabular}


mean height was $154.2 \pm 10.8 \mathrm{~cm}(\min =120, \max =189)$, their mean weight was $46.1 \pm 11.8 \mathrm{~kg}(\min =25, \max =95)$ and the mean $\mathrm{BMI}$ percentile was $53.8 \pm 33.7$ ( $\min =1.03$, $\max =100.0$ ). The ratio of the students who said that they spent half an hour per day with computers was $22.8 \%(n=96), 24.7 \%$ said that they spent half an hour per day with phones $(n=104)$, and $27.1 \%$ said that they watched an hour of television per day $(n=114)$. Of the students, $75 \%$ said that they had breakfast every day ( $n=316), 41.3 \%$ said that they consumed junk food every 2 or 3 days ( $n=174$ ), and $24.9 \%$ said that they consumed fast food once a week $(n=105)$. The ratio of the students who were content with the appearance of their bodies was $66.3 \%(n=279)$, and $14.3 \%$ of the students said that they were discontented with the appearance of their bodies $(n=60)$.

\section{Family Characteristics}

The mean height of the mothers was $164.5 \pm 5.6 \mathrm{~cm}$ ( $\min =136, \max =185)$. Their mean weight was $65.3 \pm 8.8 \mathrm{~kg}$ ( $\min =35$, max $=105)$, and their mean BMI was $23.7 \pm 3.3$ $(\min =8, \max =37)$. According to the $B M I$ values, $5 \%$ of the mothers were underweight $(n=21), 73.9 \%$ had a normal weight $(n=311), 14.5 \%$ were overweight $(n=61)$, and $6.7 \%$ were obese $(n=28)$. The mean height of the fathers was $176.8 \pm 15.9 \mathrm{~cm}(\min =176, \max =198)$. Their mean weight was $81.0 \pm 8.7 \mathrm{~kg}(\min =55, \max =130)$, and their mean BMI was $25.1 \pm 2.6$ ( $\min =17, \max =40)$. According to the BMI values, $1 \%$ of the fathers were underweight $(n=4), 28.7 \%$ had a normal weight $(n=121), 65.1 \%$ were overweight $(n=274)$, and $5.2 \%$ were obese $(n=22)$. There was no relationship between the children's BMI percentile and their mother's BMI values ( $\left.x^{2}=17.191, p=0.066\right)$ and their father's BMI values $\left(x^{2}=10.839, p=0.287\right)$.
The Obesity Awareness and Emotional Eating Levels of Middle School Students and the Relationships Between Obesity, Obesity Awareness, and Emotional Eating

The mean total score on the EES-C of the children was $50.4 \pm 14.8$. The mean total score on the OAS of the children was $56.3 \pm 9.4$ (Table II).

There was no relationship between obesity, obesity awareness, and emotional eating ( $>>0.05)$. There was a high positive relationship between the EES-C and its subdimensions $(p<0.001)$, and the OAS and its subdimensions $(p<0.001)$ (Table III).

\section{Discussion}

Pediatric loss of eating control in children is a problematic behavior that frequently persists into adolescence and is related to emotional distress (20). Emotional eating is reported to be a learned behavior and described as eating in response to an emotional state. Emotional overeating is associated with an increased risk of obesity, while emotional undereating may prevent childhood obesity (21). Nguyen-Michel et al. (22) found that emotional eating is associated with the frequent intake of high calorie fatty and sugary foods in Latino middle school students. They stated that emotional eating may lead to overeating. Emotional overeating among adolescents can lead to obesity (23). Sánchez et al. (10) found a significant relationship between Chilean children's eating behavior scores and BMI Z-scores. Tong et al. (9) reported that there was no relationship between Asian children's emotional eating and BMI. Nogay (24) found that BMI was significantly correlated with emotional eating subscales in Turkish adolescents. In another study, there was no significant correlation between

Table II. Obesity awareness and emotional eating levels of the middle school students

\begin{tabular}{|c|c|c|c|c|c|c|}
\hline & $\begin{array}{l}\text { Obese } \\
(n=62)\end{array}$ & $\begin{array}{l}\text { Overweight } \\
(n=58)\end{array}$ & $\begin{array}{l}\text { Normal weight } \\
(n=261)\end{array}$ & $\begin{array}{l}\text { Underweight } \\
(n=40)\end{array}$ & $\begin{array}{l}\text { Total } \\
(n=421)\end{array}$ & $\mathbf{p}$ \\
\hline EES-C-AAF & $24.2 \pm 8.5(13-52)$ & $24.6 \pm 8.0(13-37)$ & $24.0 \pm 8.3(13-65)$ & $26.1 \pm 9.0(13-44)$ & $24.3 \pm 8.4(13-65)$ & 0.521 \\
\hline EES-C-UNS & $9.5 \pm 2.9(5-15)$ & $9.3 \pm 3.5(5-18)$ & $9.6 \pm 3.3(5-25)$ & $9.6 \pm 3.5(5-19)$ & $9.6 \pm 3.3(5-25)$ & 0.926 \\
\hline EES-C-DEP & $16.2 \pm 4.8(8-28)$ & $15.9 \pm 5.5(7-28)$ & $16.6 \pm 5.1(7-33)$ & $16.4 \pm 5.5(7-30)$ & $16.4 \pm 5.1(7-33)$ & 0.808 \\
\hline EES-C total & $50.0 \pm 13.6(30-92)$ & $50.0 \pm 15.1(25-75)$ & $50.4 \pm 14.8(25-121)$ & $52.2 \pm 16.2(25-85)$ & $50.4 \pm 14.8(25-121)$ & 0.877 \\
\hline Obesity awareness & $24.5 \pm 4.4(12-32)$ & $23.4 \pm 4.9(10-35)$ & $24.0 \pm 3.8(11-36)$ & $23.9 \pm 4.4(15-34)$ & $24.0 \pm 4.1(10-36)$ & 0.560 \\
\hline Nutrition & $18.1 \pm 3.8(6-24)$ & $17.4 \pm 4.0(6-24)$ & $17.9 \pm 3.7(7-24)$ & $18.3 \pm 3.5(7-24)$ & $17.9 \pm 3.7(6-24)$ & 0.625 \\
\hline Physical activity & $14.2 \pm 2.8(5-20)$ & $14.4 \pm 3.3(5-20)$ & $14.4 \pm 3.0(5-20)$ & $14.7 \pm 3.5(5-20)$ & $14.4 \pm 3.0(5-20)$ & 0.883 \\
\hline OAS Total & $56.9 \pm 9.8(24-69)$ & $55.2 \pm 10.8(22-79)$ & $56.4 \pm 8.8(26-80)$ & $57.1 \pm 10.2(28-77)$ & $50.4 \pm 14.8(25-121)$ & 0.747 \\
\hline
\end{tabular}


Table III. The relationship between obesity, obesity awareness and emotional eating scores

\begin{tabular}{|c|c|c|c|c|c|c|c|c|c|}
\hline & 1 & 2 & 3 & 4 & 5 & 6 & 7 & 8 & 9 \\
\hline 1. Obesity & 1.0 & - & - & - & - & - & - & - & - \\
\hline 2. EES-C-AAF & -0.084 & 1.0 & - & - & - & - & - & - & - \\
\hline 3. EES-C-UNS & -0.018 & $0.693^{* *}$ & 1.0 & - & - & - & - & - & - \\
\hline 4. EES-C-DEP & $-0.127^{* *}$ & $0.619^{* *}$ & $0.513^{* *}$ & 1.0 & - & - & - & - & - \\
\hline 5. EES-C total & -0.095 & $0.932^{* *}$ & $0.791^{* *}$ & $0.822^{* *}$ & 1.0 & - & - & - & - \\
\hline 6. Obesity awareness & $0.112^{*}$ & -0.068 & -0.001 & -0.036 & -0.054 & 1.0 & - & - & - \\
\hline 7. Nutrition & 0.004 & -0.031 & -0.010 & -0.011 & -0.022 & $0.506^{* *}$ & 1.0 & - & - \\
\hline 8. Physical activity & 0.003 & -0.009 & -0.038 & -0.018 & -0.017 & $0.374^{* *}$ & $0.599^{* *}$ & 1.0 & - \\
\hline 9. OAS total & 0.067 & -0.054 & -0.024 & -0.039 & -0.049 & $0.812^{* *}$ & $0.831^{* *}$ & $0.728^{* *}$ & 1.0 \\
\hline
\end{tabular}

${ }^{*}$ Correlation is significant at the 0.05 level (2-tailed), ${ }^{* *}$ Correlation is significant at the 0.01 level (2-tailed).

EES-C: Emotional Eating scale, EES-C-AAF: Anxiety, anger, and frustration, EES-C-DEP: Depressive symptoms, EES-C-UNS: Feeling unsettled, OAS: Obesity Awareness scale

emotional eating and BMI in early adolescent girls (25). This study also found no relationship between children's obesity and emotional eating. This may be attributed to the low mean emotional eating scores of the children in the study. It has been reported that depressive symptoms predict eating disorders (26). In another study, emotional abuse was determined to be a risk factor for eating disorders and had a relationship with BMI (27). Erickson et al. (28) determined a strong relationship between depressive symptoms and BMI, especially for girls. Fox et al. (29) reported that severe obesity versus obesity was 3.5 times higher than normal for depressed adolescents. We found no relationship between depressive symptoms and obesity. Emotional eating-depressive symptoms subdimension scores were similar for obese and non-obese children.

In countries that lack school health programs, there is a need to increase awareness of prevention against becoming overweight or obesity (30). There have been studies of parents' obesity awareness. One reported that most of the parents incorrectly classified the weights of their children and could not tell if their children were overweight or obese (31). Today, obesity, as an increasing health problem, has compelled educators to carry out programs to raise children's obesity awareness (32).

O'Dea and Wilson (33) determined that there was no relationship between $\mathrm{BMI}$ and nutritional knowledge and also dietary control. Similarly, this study found no relationship between obesity and obesity awareness. This may be attributed to the high obesity awareness among most of the children in this study. Family-oriented health programs to control childhood obesity have been organized and are reported to be effective (34). Raising obesity awareness among all family members and not just children is necessary. This study found no relationship between obesity awareness, emotional eating, and obesity. The children included in this study received low scores on the EES-C and had a high mean score on the OAS. These scores and the low ratios of overweight and obese children led us to conclude that the school children in this study were aware of their eating habits and obesity. In another relevant study, the predictors regarding children, their families, and school context variables were found to affect children's obesity (35). Other factors which can affect children's obesity should also be identified.

\section{Study Limitations}

No randomization was used in sample selection. In this study, obese and non-obese children could be compared using a suitable sampling method.

\section{Conclusion}

This study determined that there was no relationship between obesity, emotional eating, and obesity awareness. Obesity awareness and emotional eating both failed to explain middle school children's obesity. In a sample with more obese children, this type of study can be repeated. Additional research should examine the specific roles of emotional eating in the development of obesity in adolescents. These studies can be useful for preventing obesity and emotional eating. Longitudinal studies should be conducted to determine factors causing obesity. The knowledge and awareness of children and parents should be increased through healthy eating and physical activity programs.

\section{Ethics}

Ethics Committee Approval: The written consent of Dokuz Eylül University Non-invasive Research Ethics Board 
was obtained in a decision numbered (3019-GOA, 2016/2925).

Informed Consent: Informed written consent from parents was received through the children. Verbal consent from the children was also received.

Peer-review: Externally peer-reviewed.

\section{Authorship Contributions}

Concept: G.Ö.G., M.B., Design: G.Ö.G., M.B., Data Collection or Processing: G.Ö.G., Analysis or Interpretation: G.Ö.G., M.B., Literature Search: G.Ö.G., M.B., Writing: G.Ö.G., M.B.

Conflict of Interest: None of the authors had conflict of interest.

Financial Disclosure: The authors declared that this study received no financial support.

\section{References}

1. Savage IS, Fisher JO, Birch LL. Parental influence on eating behavior: conception to adolescence. I Law Med Ethics 2007; 35:22-34.

2. Bekker $\mathrm{MHJ}$, van de Meerendonk C, Mollerus J. Effects of negative mood induction and impulsivity on self-perceived emotional eating. Int J Eat Disord 2004; 36:461-9.

3. Croker H, Cooke L, Wardle J. Appetitive behaviours of children attending obesity treatment. Appetite 2011; 57:525-9.

4. CDC. Obesity Prevention, Healthy Schools, CDC. 2015. Available from: https://www.cdc.gov/healthyschools/obesity/facts.htm

5. Ogden $C L$, Carroll MD, Kit BK, Flegal KM. Prevalence of Childhood and Adult Obesity in the United States, 2011-2012. JAMA 2014; 311:806.

6. T.C. Sağlık Bakanlığı Temel Sağlık Hizmetleri Genel Müdürlüğü. Türkiye'de Okul Çağı Çocuklarında Büyümenin İzlenmesi Projesi, 2011. Available from: www.kubanmatbaa.com

7. Demir D, Bektas M. The effect of childrens' eating behaviors and parental feeding style on childhood obesity. Eat Behav 2017; 26:137-42.

8. Reicks M, Banna J, Cluskey $M$, et al. Influence of Parenting Practices on Eating Behaviors of Early Adolescents during Independent Eating Occasions: Implications for Obesity Prevention. Nutrients 2015; 7:8783-801.

9. Tong L, Shi H, Li X. Associations among ADHD, Abnormal Eating and Overweight in a non-clinical sample of Asian children. Sci Rep 2017; 7:2844.

10. Sánchez U, Weisstaub G, Santos JL, et al. COCS cohort: children's eating behavior scores and BMI. Eur J Clin Nutr 2016; 70:925-8.

11. Jalo $\mathrm{E}$, Konttinen $\mathrm{H}$, Vepsäläinen $\mathrm{H}$, et al. Emotional Eating, Health Behaviours, and Obesity in Children: A 12-Country CrossSectional Study. Nutrients 2019; 11:1-17.

12. Péneau S, Ménard E, Méjean C, Bellisle F, Hercberg S. Sex and dieting modify the association between emotional eating and weight status. Am J Clin Nutr 2013; 97:1307-13.
13. Bozbulut R, Ertaş-Öztürk Y, Döğer E, Bideci A, Köksal E. Increased Obesity Awareness and Adherence to Healthy Lifestyle-Diet Reduce Metabolic Syndrome Risk in Overweight Children. I Am Coll Nutr 2019; 1-6.

14. Perpiñá C, Cebolla A, Botella C, Lurbe E, Torró M-I. Emotional Eating Scale for Children and Adolescents: Psychometric Characteristics in a Spanish Sample. I Clin Child Adolesc Psychol 2011; 40:424-33.

15. Neyzi $O$, Günöz H, Furman A, et al. Body weight, height, head circumference and body mass index reference values in Turkish children. Çocuk Sağlığı ve Hast Derg 2008; 51:1-14.

16. Allen A. Effects of Educational Intervention on Children's Knowledge of Obesity Risk Factors. Phd Thesis, Carroll College, 2011. Available from: https://www.carroll.edu/nursing/studentsuccesses

17. Kafkas ME, Özen G. The Turkish Adaptation of the Obesity awareness Scale: A validity and reliability study. İnönü Üniversitesi Beden Eğitimi ve Spor Bilim Derg 2014; 1:1-15.

18. Tanofsky-Kraff M, Theim KR, Yanovski SZ, et al. Validation of the emotional eating scale adapted for use in children and adolescents (EES-C). Int J Eat Disord 2007; 40:232-40.

19. Bektas M, Bektas I, Selekoğlu Y, Kudubes AA, Altan SS, Ayar D. Psychometric properties of the Turkish version of the Emotional Eating Scale for children and adolescents. Eat Behav 2016; 22:217-21.

20. Tanofsky-Kraff M, Shomaker LB, Olsen C, et al. A prospective study of pediatric loss of control eating and psychological outcomes. I Abnorm Psychol 2011; 120:108-18.

21. Herle $\mathrm{M}$, Fildes $\mathrm{A}$, Steinsbekk S, Rijsdijk F, Llewellyn $\mathrm{CH}$. Emotional over- and under-eating in early childhood are learned not inherited. Sci Rep 2017; 7:9092.

22. Nguyen-Michel ST, Unger JB, Spruijt-Metz D. Dietary correlates of emotional eating in adolescence. Appetite 2007; 49:494-9.

23. Bagherniya $M$, Darani $F M$, Sharma $M$, Allipour-Birgani $R$, Taghipour A, Safarian M. Qualitative study to determine stressors influencing dietary and physical activity behaviors of overweight and obese adolescents in Iran. Int I Prev Med 2019; 10:189.

24. Nogay $\mathrm{NH}$. The role of psychological eating styles in obesity among Turkish adolescents: A cross-sectional study. I Pak Med Assoc 2017; 67:573-6.

25. Banna JC, Panizza CE, Boushey C), Delp E), Lim E. Association between cognitive restraint, uncontrolled eating, emotional eating and BMI and the amount of food wasted in early adolescent girls. Nutrients 2018; 10:1279.

26. Measelle JR, Stice E, Hogansen JM. Developmental Trajectories of Co-Occurring Depressive, Eating, Antisocial, and Substance Abuse Problems in Adolescent Girls. I Abnorm Psychol 2006; 115:524-38.

27. Hymowitz G, Salwen J, Salis KL. A mediational model of obesity related disordered eating: The roles of childhood emotional abuse and self-perception. Eat Behav 2017; 26:27-32.

28. Erickson SJ, Robinson TN, Haydel KF, Killen JD. Are Overweight Children Unhappy? Arch Pediatr Adolesc Med 2000; 154:931. 
29. Fox CK, Gross AC, Rudser KD, Foy AMH, Kelly AS. Depression, Anxiety, and Severity of Obesity in Adolescents. Clin Pediatr 2016; 55:1120-5.

30. Pradeilles R, Rousham EK, Norris SA, Kesten JM, Griffiths PL. Community readiness for adolescents' overweight and obesity prevention is low in urban South Africa: a case study. BMC Public Health 2016; 16:763.

31. Al-Mohaimeed A. Parents' perception of children's obesity. I Fam Community Med 2016; 23:179.

32. Xu F, Ware RS, Leslie E, et al. Effectiveness of a Randomized Controlled Lifestyle Intervention to Prevent Obesity among Chinese Primary School Students: CLICK-Obesity Study. PLoS One 2015; 10:e0141421.
33. O'Dea JA, Wilson R. Socio-cognitive and nutritional factors associated with body mass index in children and adolescents: possibilities for childhood obesity prevention. Health Educ Res 2006; 21:796-805.

34. Robertson W, Fleming J, Kamal A, et al. Randomised controlled trial evaluating the effectiveness and cost-effectiveness of 'Families for Health', a family-based childhood obesity treatment intervention delivered in a community setting for ages 6 to 11 years. Health Technol Assess 2017; 21:1-180.

35. Henrique RS, Gomes TN, Tani G, Maia JAR. Association between body mass index and individual characteristics and the school context: a multilevel study with Portuguese children. / Pediatr 2018; 94:313-9. 